\title{
Analysis of Electrical Arc Furnace Flue Dusts by Spark Ablation Inductively Coupled Plasma Atomic Emission Spectrometry*
}

\author{
A. G. Coedo, M. T. Dorado and I. G. Cobo \\ Centro Nacional de Investigaciónes Metalúrgicas, Consejo Superior de Investigaciónes Cientifícas, \\ Gregorio del Amo. 8, 28040 Madrid, Spain
}

\begin{abstract}
A medium-voltage spark was used for the direct nebulization of electric arc furnace (EAF) flue dust. In order to attain the necessary sample conductivity, powder pellets are briquetted after mixing the sample $1+1$ with graphite. The elutriated material was excited in an argon inductively coupled plasma (ICP). The use of cellulose as binder provides better results in terms of reproducibility. After optimization of the spark parameters (voltage, $500 \mathrm{~V}$; repetition rate, $400 \mathrm{~s}^{-1}$; and resistance, $\left.2.2 \Omega\right)$, the carrier gas flow rate $\left(2.1 \mathrm{I} \mathrm{min}^{-1}\right.$ of argon) and the operating power of the ICP $(1.2 \mathrm{~kW})$, precisions (relative standard deviation) for zinc, lead, cadmium and iron range from 0.8 to $2.0 \%$. The stability of the spark sampling, during a complete spark ablation $(S A)$ ICP process ( $\approx 90 \mathrm{~s}$ ) was tested by plotting emission intensity versus time profiles. The similarity between the amounts of analyte obtained from different pellets was proven by collecting the spark-eroded particles and analysing their carbon contents. Five steelmaking EAF flue dusts were selected for this study, using the two samples with extreme contents of the elements considered, for calibration. The results obtained by SA-ICP matched the results obtained by ICP from nebulized solutions.
\end{abstract}

Keywords: Spark sampling; non-conductive powder; steel making; dust analysis; spark ablation inductively coupled plasma atomic emission spectrometry

The environmental pollution caused by residues from electric arc furnace flue dusts, which are considered to be toxic and hazardous products, poses a real problem for the iron and steel industry. The use of galvanized sheets is becoming more widespread, and when this material is recycled in electric arc furnaces it produces dusts containing $\mathrm{Zn}, \mathrm{Pb}$ and $\mathrm{Cd}$, which can be leached into the natural environment and can therefore accumulate in soil and water. Technological processes for treating these powders are being developed intensely at the present time. ${ }^{1,2}$ Optimization of these processes requires application of analytical control methods that ensure high sensitivity and selectivity combined with acceptable accuracy and speed. Inductively coupled plasma atomic emission spectrometry (ICP-AES) meets these requirements, making possible the analytical follow-up of such processes. The system normally used is a sample dissolution step followed by ICP-AES, yet this procedure is hampered by the dissolution of some of the refractory oxides that can be present. Acid digestion and alkali fusion of the insoluble residue is the conventional sample dissolution procedure. This dissolution procedure reduces the power of detection, as a result of analyte dilution and high saline concentration, and is time-consuming and labour intensive. Spark ablation has been applied for bulk analysis of conducting solids ${ }^{3}$ and powder samples ${ }^{4}$ and can simplify the ICP analytical process by eliminating the dissolution step. One possible form of preparing non-conductive powder for spark ablation (SA) sampling is to briquette the powder into pellets with a metallic powder to achieve the necessary conductivity. $5,6,7$

This study aims to ascertain the feasibility of the SA-ICP technique for the analysis of steelmaking flue dusts. Different pellet preparation procedures were investigated to obtain physically stable test samples, with adequate conductivity and the optimum proportion of the components, dust, conducting powder and binder. The influence of sparking operating parameters (voltage, resistance and repetition rate) was studied, the total amount of eroded material was controlled and the analytical performance of the technique evaluated. A precision test was conducted to ascertain the repeatability of the ICP measurements and the reproducibility of the sample prep-

* Presented at the XXVIII Colloquium Spectroscopicum Internationale (CSI), York, UK, June 29-July 4, 1993. aration system. Finally, the results obtained for the selected samples, by using the proposed method, and the corresponding standard deviations (SDs), are presented.

\section{Experimental}

\section{Instrumentation}

A JY-SAS sparking unit was used as the solid sampling source. The ablated material was excited in a JY 24 ICP spectrometer. Instrumental details and working conditions are listed in Table 1.

\section{Samples}

Representative samples of electric arc furnace (EAF) flue dust were selected for the development of the SA-ICP analytical procedures. Consideration was first given to the information provided by different steelmaking companies on the types of steel they manufacture, their steel production and the flue dust generated during the steelmaking process. These samples were initially analysed by ICP spectrometry from nebulized solutions obtained with the following dissolution procedure: $0.200 \mathrm{~g}$ of sample was fused at $1200^{\circ} \mathrm{C}$ in a Pt crucible with $1 \mathrm{~g}$ of the flux mixture consisting of borax and sodium carbonate $(1: 1)$.

Table 1 Optimized working conditions for SA-ICP

\begin{tabular}{ll}
\hline $\begin{array}{l}\text { Sparking parameters } \\
\text { Voltage } / \mathrm{V}\end{array}$ & 500 \\
Capacitance $/ \mu \mathrm{F}$ & 1 \\
Inductance $/ \mu \mathrm{H}$ & 20 \\
Resistance $/ \Omega$ & 2.2 \\
Repetition rate & $400 \mathrm{~s}^{-1}$ \\
Electrode (cathode) & Tungsten rod, $\theta=2 \mathrm{~mm}$ \\
Transport & \\
Permanent carrier gas $/ 1 \mathrm{~min}^{-1}$ & 2.1 \\
Analysis carrier gas $/ 1 \mathrm{~min}^{-1}$ & 0.8 \\
Carrier gas pressure/bar & 3 \\
Distance $/ \mathrm{m}$ & 1 \\
Diameter of the transport tube $/ \mathrm{mm}$ & 5 \\
ICP & \\
Power $/ \mathrm{kW}$ & 1.2 \\
Plasma gas $/ 1 \mathrm{~min}^{-1}$ & 14 \\
Sheath gas $/ 1 \mathrm{~min}^{-1}$ & 0.2
\end{tabular}


Table 2 Composition of EAF flue dusts (ICP pneumatic nebulization; $n:=6$ )

\begin{tabular}{|c|c|c|c|c|c|c|c|c|}
\hline \multirow[b]{2}{*}{ Sample } & \multicolumn{2}{|c|}{$\operatorname{Zn}(\%)$} & \multicolumn{2}{|c|}{$\mathrm{Pb}(\%)$} & \multicolumn{2}{|c|}{$\mathrm{CD}(\%)$} & \multicolumn{2}{|c|}{$\mathrm{Fe}(\%)$} \\
\hline & $x$ & $\sigma$ & $x$ & $\sigma$ & $x$ & $\sigma$ & $x$ & $\sigma$ \\
\hline DUST 1 & 12.52 & 0.07 & 2.76 & 0.05 & 0.041 & 0.001 & 34.75 & 0.18 \\
\hline DUST 2 & 24.61 & 0.15 & 5.33 & 0.12 & 0.47 & 0.005 & 15.51 & 0.15 \\
\hline DUST 3 & 36.00 & 0.20 & 11.21 & 0.10 & \multicolumn{2}{|c|}{$<0.01$} & 8.55 & 0.09 \\
\hline DUST 4 & 44.22 & 0.21 & 9.60 & 0.11 & 2.001 & 0.019 & 4.92 & 0.06 \\
\hline DUST 5 & 46.18 & 0.23 & 15.14 & 0.20 & \multicolumn{2}{|c|}{$<0.01$} & 0.88 & 0.05 \\
\hline
\end{tabular}

The melt was digested with water and dissolved by adding $3 \mathrm{ml}$ of $65 \% \mathrm{HNO}_{3}+1 \mathrm{ml}$ of $37 \% \mathrm{HCl}$. The final volume of the resulting solution was adjusted to $200 \mathrm{ml}$ with water. The samples selected and their composition, presented as the average of six values obtained by two different operators with ICP-AES from nebulized solutions, are listed in Table 2.

\section{Pellet preparation}

A $4 \mathrm{~g}$ portion of sample $+4 \mathrm{~g}$ of graphite $+2 \mathrm{~g}$ of cellulose were mixed and homogenized in a ball mixer/mill, and pressed into a pellet $(\theta=4 \mathrm{~cm}$; thickness $=10 \mathrm{~mm})$ with a load of $40 \mathrm{t} \mathrm{cm}^{-2}$ for $30 \mathrm{~s}$, in a hydraulic press.

\section{Results and Discussion}

\section{Sample Preparation}

Various tests were performed to define suitable procedures for obtaining stable pellets with the necessary conductivity. The main advantage of flue dusts is their extremely fine particle size $(95 \%$ have a particle size of less than $0.5 \mu \mathrm{m})$, which makes these products suitable for direct compaction.

The matrix was modified by mixture with a conducting host material. The conducting powders tested were: copper, aluminium and graphite. The criteria used to select the most appropriate diluent powder were: high conductivity, ease of handling, low cost, acquisition of bulk samples providing stable and reproducible responses to electric discharges and absence of inter-elemental spectral interferences. Copper produces spectral interferences in the two most sensitive analytical $\mathrm{Zn}$ lines ( $\mathrm{Zn} 213.856 \mathrm{~nm}$ is interfered with by $\mathrm{Cu} 213.853$ and $\mathrm{Zn}$ $202.548 \mathrm{~nm}$ is interfered with by $\mathrm{Cu} 202.434-202.555 \mathrm{~nm}$ ) and the presence of aluminium powder results in deep erosion and consequently to a massive input of sample, even when using very low voltages, which decreases the plasma stability. The use of graphite as diluent provides the best results and consequently this conductive powder was selected for further tests.

The addition of a binder improves the mechanical properties of the pellets, enables a better ablation to be carried out and increases the reproducibility of the eroded material. The two binders tested were: $N$-butyl methacrylate (Elvacite) and cellulose. Binding with cellulose provides the best results in terms of precision of the SA-ICP results.

Another essential aspect of pellet preparation is the ratio of sample to conductive powder and binder. Different proportions of the components were tested: $2+1+0.5 ; 2+1+1 ; 1+1+0.5$; $1+2+0.5$ and $2+2+0.5$. With the dilution ratio $1+1+0.5$ for sample:graphite:cellulose, the optimum mechanical properties of the pellets and good conductivity were achieved. Unlike spark emission, the conductivity of the pellets is not of primary importance because the spark in this case only performs ablation, while excitation is achieved by the ICP. Consequently, the pellet preparation procedure described above was adopted.

The analytical line sensitivity and spectral interferences were studied by using solutions containing approximately the background equivalent concentration (BEC) of the element being investigated and the maximum expected concentrations of all the others. This study showed that by using graphite as conductive material, the most sensitive lines listed in ref. 8 can be used for the determination of the elements being studied using an ICP: $\mathrm{Zn}=213.856 \mathrm{~nm}, \mathrm{~Pb}=220.353 \mathrm{~nm}, \mathrm{Cd}=$ $214.438 \mathrm{~nm}$ and $\mathrm{Fe}=259.940 \mathrm{~nm}$.

\section{Optimization of Spark Sampling}

Spark ablation conditions are defined by the following three parameters: voltage $(V)$, resistance $(R)$ and repetition rate $(f)$. The mildest practical condition for SA is obtained with the following parameters: $V=350 \mathrm{~V}, R=2.2 \Omega$ and $f=400 \mathrm{~Hz}$, no application work was performed for lower frequencies owing to the poor sensitivity and repeatability obtained. Harsher conditions are obtained by decreasing resistance and increasing voltage. Lower resistance values increase the amount of analyte significantly, causing material to be deposited in the injector tube of the plasma torch and signal instabilities. Consequently, the sparking conditions were optimized by keeping the maximum repetition rate and highest resistance available $\left(400 \mathrm{~s}^{-1}\right.$ and $2.2 \Omega$, respectively) and varying the voltage between 350 and $700 \mathrm{~V}$.

By increasing the condenser voltage, it is possible to introduce more material into the ICP. This was shown by measuring the amounts of carbon from the released aerosol trapped on $47 \mathrm{~mm}$ diameter glass microfibre filters with a pore size of $0.3 \mu \mathrm{m}$. Taking into consideration the intensities and precisions of the ICP measurements, the voltage selected was $500 \mathrm{~V}$. At 350 and $400 \mathrm{~V}$ the sensitivity and precision are poorer than those attained at $500 \mathrm{~V}$; at $600 \mathrm{~V}$ the analytical signal becomes unstable as flickering occurs in the ICP, as a result of an important increase in the amount of sample ablated, which causes incomplete particle volatilization in the plasma.

Table 3 shows the amount of graphite eroded at various voltages and the corresponding $\mathrm{Zn}$ emission intensities, obtained from pellets of the sample 'DUST 2'.

The intensity versus time curves, Fig. 1, show the stability of the emission for the elements considered, from $10 \mathrm{~s}$ (pre-spark time) to at least $90 \mathrm{~s}$. This is sufficient time to analyse the four elements considered in the same analytical programme. In an effort to minimize sparking times, peak intensities were measured employing a 'three-point' mode. In this mode, the windows include three points with a distance between them of $0.0003 \mathrm{~nm}$, and the intensity value is a weighted average of these three points.

Table 3 Eroded graphite and $\mathrm{Zn}$ emission intensities (arbitrary units) at various condenser voltages (pellets from sample 'DUST 2')

\begin{tabular}{lccc}
\hline & & \multicolumn{2}{c}{$\mathrm{Zn}$} \\
\cline { 3 - 4 }$V / \mathrm{V}$ & $\mathrm{C}^{*} / \mathrm{mg} \mathrm{min}^{-1}$ & 200 & $\mathrm{RSD}$ \\
350 & 1.8 & 220 & 2.6 \\
400 & 2.8 & 250 & 2.5 \\
500 & 3.5 & 310 & 1.9 \\
600 & 4.3 & Intensity $\times 10^{3}$ & 3.4 \\
\hline
\end{tabular}

* Carbon determination was performed by infrared absorption after combustion in an induction furnace. 
Table 4 Analysis of EAF flue dusts by SA-ICP; $n=6$

\begin{tabular}{|c|c|c|c|c|c|c|c|c|}
\hline \multirow[b]{2}{*}{ Sample } & \multicolumn{2}{|c|}{$\mathrm{Zn}(\%)$} & \multicolumn{2}{|c|}{$\mathrm{Pb}(\%)$} & \multicolumn{2}{|c|}{$\mathrm{Cd}(\%)$} & \multicolumn{2}{|c|}{$\mathrm{Fe}(\%)$} \\
\hline & $x$ & $\sigma$ & $x$ & $\sigma$ & $x$ & $\sigma$ & $x$ & $\sigma$ \\
\hline DUST 1 & \multicolumn{2}{|c|}{ Calibration 'low' } & \multicolumn{2}{|c|}{ Calibration 'low' } & 0.038 & 0.001 & \multicolumn{2}{|c|}{ Calibration 'high' } \\
\hline DUST 2 & 24.40 & 0.50 & 5.00 & 0.11 & 0.46 & 0.01 & 15.21 & 0.20 \\
\hline DUST 3 & 35.81 & 0.49 & 11.52 & 0.25 & \multicolumn{2}{|c|}{$<0.01$} & 8.33 & 0.20 \\
\hline DUST 4 & 43.65 & 0.85 & 9.43 & 0.10 & \multirow{2}{*}{\multicolumn{2}{|c|}{$\begin{array}{l}\text { Calibration 'high' } \\
\text { Calibration 'low' }\end{array}$}} & 4.70 & 0.10 \\
\hline DUST 5 & Calibr & high' & Calibra & igh' & & & \multicolumn{2}{|c|}{ Calibration 'low' } \\
\hline ECRM 876-1 & $\begin{array}{c}\text { Certified } \\
23.29\end{array}$ & $\begin{array}{c}\text { Found } \\
23.58\end{array}$ & $\begin{array}{l}\text { Certified } \\
7.82\end{array}$ & $\begin{array}{l}\text { Found } \\
7.54\end{array}$ & $\begin{array}{c}\text { Certified } \\
0.13\end{array}$ & $\begin{array}{c}\text { Found } \\
0.11\end{array}$ & $\begin{array}{c}\text { Certified } \\
24.85\end{array}$ & $\begin{array}{c}\text { Found } \\
25.12\end{array}$ \\
\hline$\sigma$ & 0.32 & 0.45 & 0.23 & 0.20 & 0.01 & 0.01 & 0.17 & 0.22 \\
\hline
\end{tabular}

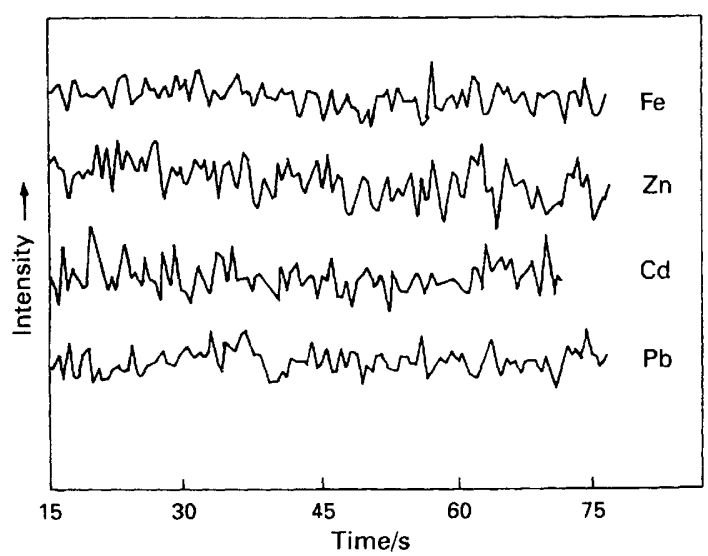

Fig. 1 Sparking curves (intensity versus time)

\section{ICP Calibration}

After verifying the linearity of the emission intensities versus concentrations of the elements studied, within the intervals of contents considered, only two of the DUST samples were used to obtain the calibration graphs: 'DUST 1' and 'DUST 5' for $\mathrm{Zn}, \mathrm{Pb}$ and $\mathrm{Fe}$ determination and 'DUST 1' and 'DUST 4' for $\mathrm{Cd}$ analysis. The remaining DUST samples were analysed as unknowns.

The scans around the selected analytical lines of the two calibration samples are shown in Fig. 2. The relative intensities and the absence of spectral interferences can be appreciated.

The aforementioned calibrations were used to analyse the other selected steelmaking dusts. The accuracy of the proposed method was tested by analysing one electrical furnace dust reference material: Euronorm Certified Reference Material, ECRM 876-1. The calculated mean values, obtained from the three measurements of each of three identically prepared samples, and the corresponding SDs are shown in Table 4.

Precision tests were performed using pellets from 'DUST 1' and 'DUST 5'. The procedure described above was used to prepare six pellets of each sample. The instrumental variability was tested by measuring one pellet of each sample ten times; RSD $<1.5 \%$ for both samples, with the majority of the values lying between 0.7 and $1.2 \%$. The total variance (influenced by the difference between samples) was assessed by measuring the six pellets of each sample ten times also; RSDs ranged from 0.75-1.9 and $0.80-2.0$ for DUST 1 and DUST 5, respectively. The corresponding RSD values obtained by ICP-AES from nebulized solutions were $<0.5$ and $<0.7 \%$, respectively for DUST 1 and DUST 5.

The analytical performance expressed in terms of background equivalent concentration (BEC) and detection limit (DL) are given in Table 5. The DLs were calculated as the concentration of a solution giving an absorbance equal to three times the SD of the blank. Because there was no EAF flue dust that did not contain the elements being studied and

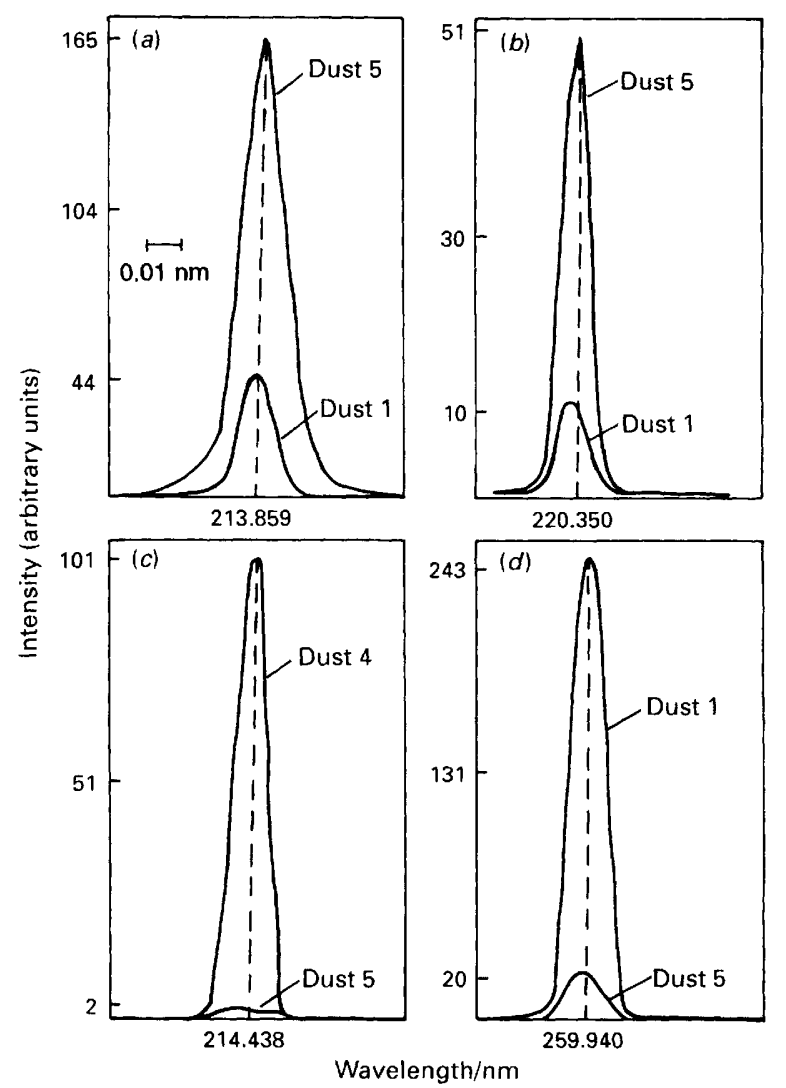

Fig. 2 Scans for sample calibration, for the analytical lines of: (a) $\mathrm{Zn}$; (b) $\mathrm{Pb} ;(c) \mathrm{Cd}$; and $(d) \mathrm{Fe}$. The scale given in $(a)$ also applies to $(b),(c)$ and $(d)$

Table 5 Analytical performance

\begin{tabular}{ccc}
\hline Element & BEC (\%) & DL $(\%)$ \\
$\mathrm{Zn}$ & 1.5 & 0.075 \\
$\mathrm{~Pb}$ & 1.0 & 0.080 \\
$\mathrm{Cd}$ & 0.05 & 0.003 \\
$\mathrm{Fe}$ & 1.2 & 0.080 \\
\hline
\end{tabular}

containing $100 \%$ of the remaining elements, off-peak measurements were estimated as on-peak values. These BEC and DL values are of the same order of magnitude as those provided by ICP-AES, using nebulized solutions obtained from an alkaline fusion of the sample.

\section{Conclusion}

With the pellet preparation procedure described, it is possible to directly analyse EAF flue dusts by using SA as the solid sampling system for ICP. The method clearly simplifies the 
conventional analytical ICP process by removing the dissolution step. By mixing the sample with graphite in a proportion of $1+1$, good conductivity is achieved and the addition of cellulose permits better ablation of the material and also improves the mechanical stability of the pellets. The amounts of carbon in the released aerosol were evaluated, in order to test the stability and the efficacy of SA, by analysing the aerosol trapped at the end of the $0.75 \mathrm{~m}$ long plastic tube (i.d. $=5 \mathrm{~mm}$ ) that connects the spark cell with the bottom of the torch. Transport losses take place along this tube, and in order to improve the precision it is necessary to clean the plastic tube periodically using an argon or air stream, in particular when a sample with much lower contents than the previous one must be analysed. The BEC and DL values are comparable to those obtained after sample dissolution $\left(1 \mathrm{~g}^{-1}\right.$ of sample), moreover, the analytical precision is sufficient for application in metal recovery processes. Consequently, it can be concluded that for these materials the proposed analytical procedure is a viable alternative to ICP-AES following sample dissolution.

\section{References}

1 López, F. A., Balcázar, N., Formoso, A., Medina, F., and Jiménez, R., Rev. Metal. (Madrid), 1990, 26, 386.

2 Cuadra, A., and Limpo, J. L., Quim. Ind. (Madrid), 1992, 38, 27.

3 Gomez Coedo, A., Dorado Lopez, M. T., Jiminez Seco, J. L., and Gutierrez Cobo, I., J. Anal. At. Spectrom., 1992, 7, 11.

4 Aziz, A., Broekaert, J. A. C., Leis, F., and Laqua, K., Spectrochim. Acta, Part B, 1984, 39, 1091.

5 Ohls, K., and Sommer, D., Fresenius' Z. Anal. Chem., 1979, 296, 241.

6 Scott, R. H., Spectrochim. Acta, Part B, 1978, 33, 123.

7 Steffan, I., ICP Inf. Newsl., 1991, 16, 10, 564.

8 Boumans, P. W. J. M., Line Coincidence Tables for ICP-AES, Pergamon Press, Oxford, 2nd edn, 1984.
Paper 3/04578A

Received July 30, 1993 Accepted September 14, 1993 